\title{
Editorial
}

\section{Wise to learn from others' mistakes}

urgical complications and unfavourable results are a burden to all - the patient, the surgeon, the hospital and the health-care system. The rising cost of health-care has today made complications and unfavourable results simply unaffordable. The absence of consensus within the surgical community on the best way to report surgical complications has hampered proper evaluation of the surgeon's work and possibly progress in the surgical field. Clavien et al. proposed a classification of complications way back in 1992, but it was for general surgeons and it took cholecystectomy as an example surgery. ${ }^{[1]}$ Translating it into plastic surgery practice and particularly aesthetic surgery practice is both illogical and impractical because here we are treating not only the body but also the mind. In aesthetic surgery particularly, the patient is otherwise normal and our effort is to surpass the normal to meet the patient's expectations. Hence, there hides the catch - Do we understand what the patient expects and do our patients understand what is surgically possible? The smaller the chiasm between patient's expectations and our surgical possibilities, the happier the patient is post-operatively and an unhappy patient is the biggest unfavourable result in our stream.

When we talk of 'unfavourable results' the first name that comes to our mind is that of Robert Goldwyn! With his epic book 'The Unfavourable Results in Plastic Surgery - Avoidance and Treatment', he gave us an opportunity to learn from someone else's mistakes. ${ }^{[2]}$ Such results are unpleasant realities and we cannot brush them under the carpet. Documenting them truthfully for posterity requires both character and conviction and an undying love for the science we practice. This book offered us 'information that we would like to obtain

\begin{tabular}{|l|l|}
\hline \multicolumn{2}{|c|}{ Access this article online } \\
\hline Quick Response Code: & Website: \\
\hline & www.ijps.org \\
\cline { 2 - 2 } & DOI: \\
\hline
\end{tabular}

at meetings and in articles, but seldom do' and this prompted us to think along similar lines and design this theme issue.

Plastic surgery today encompasses such a wide variety of surgeries ranging from paediatric plastic surgery, trauma surgery, microsurgery, cranio-maxillofacial surgery, burn surgery, hand surgery, oncoplastic surgery to the now popular aesthetic surgery that it virtually impossible to enumerate the possible pitfalls. Besides the type specific complications, we also are burdened with the general ones such as bleeding, haematoma, seroma, infection, wound margin necrosis, poor scars, nerve damage, deep vein thrombosis, anaesthetic complications and death.

Patients too can help avoid unfavourable results by quitting smoking, eating healthy diet and staying happy and having realistic expectations. Patient's perspective, i.e., quality-of-life, pain, psychological stress should also be taken into account to estimate the severity of a complication. Although this perspective is obviously crucial, the perception of patients varies greatly depending upon the patient's character, the management and the information policy of the surgeon as well as the physical condition of the patient before and after surgery. For example, patients with dramatic improvement of their clinical condition after craniofacial surgery or limb replant may accept complications of wound healing much better than those after low morbidity procedures like breast augmentation and scar revision. Then again different surgical approaches and cultural discrepancies may induce a large variability in the evaluation of a specific complication around the world. So for practicing here in India, a country blessed with great socio-cultural diversity and cursed with worst socio-economic disparity our understanding of the patient in totality becomes vital and a small hyper pigmented scar left behind after surgery may be perfectly acceptable to some but a source of constant agony to the other.

Unfavourable results are no less stressful to the surgeon. This is an occasion to be honest and sympathetic with the 
patient. We should try to understand what happened and if possible, why it happened, without assigning blame. Most importantly, we must make sure that our patient understands the solution that is offered. Often from our experience we know that the problem is temporary and will settle with time. This calls for abundance of reassurance in the face of fear and anger from the patient's side. A revision surgery should never be rushed as this is a life-boat and is to be set afloat only when all other options have dried up.

Documenting unfavourable results in words, photographs and videos are of vital importance lest others whom we train meet the same pitfall or worse still, we end up doing the same mistake all over again. If we are operating in unfamiliar territory, we always consult books and seniors who do these surgeries more often. The discussion usually churns out pearls of wisdom about not only what to do but also what not to do. Recording these pearls and pitfalls for posterity amounts to a virtual admission of our inadequacies, but in reality it is also a statement of our character.

This theme issue has been planned with this idea in mind. We want the virtuosos to talk candidly about what went wrong and why and what did they do the next time to avoid the same misfortune and by doing so we expect them to hold the fingers of the readers and teach them how to cross these huddles. Historically, surgeons have been hesitant to talk about their 'complications' or 'mistakes.' This is not only a text about complications since unfavourable results may be produced by other factors and not all complications lead to unfavourable results. This is a true attempt to improve the results of plastic surgery. An attempt has been made to bring the reader down from the rosy clouds with which so much of the literature is surfeited, to the pitfalls which await surgeon and patient alike in the hard world of reality. No aspect, no branch, no operation, no surgeon, no patient is immune from the unwanted and unexpected result. And we must learn from the mistakes of others because Thankfully we won't live long enough to make them all ourselves!

\section{Surajit Bhattacharya} Editor Indian Journal of Plastic Surgery E-mail: surajitbh@yahoo.co.in

\section{REFERENCES}

1. Clavien PA, Sanabria JR, Strasberg SM. Proposed classification of complications of surgery with examples of utility in cholecystectomy. Surgery 1992;111:518-26.

2. Goldwyn RM, Cohen MN. The Unfavorable Results in Plastic Surgery. $3^{\text {rd }}$ ed. Boston: Little Brown and Company; 2001.

How to cite this article: Bhattacharya $S$. Wise to learn from others' mistakes. Indian J Plast Surg 2013;46:165-6.

Announcement

\section{“QUICK RESPONSE CODE” LINK FOR FULL TEXT ARTICLES}

The journal issue has a unique new feature for reaching to the journal's website without typing a single letter. Each article on its first page has a "Quick Response Code". Using any mobile or other hand-held device with camera and GPRS/other internet source, one can reach to the full text of that particular article on the journal's website. Start a QR-code reading software (see list of free applications from http://tinyurl.com/yzlh2tc) and point the camera to the QR-code printed in the journal. It will automatically take you to the HTML full text of that article. One can also use a desktop or laptop with web camera for similar functionality. See http://tinyurl.com/2bw7fn3 or http://tinyurl.com/3ysr3me for the free applications. 